\title{
Fuzzy Logic Optimization for Low Sulphur and Phosphorus in Submerged Arc Weldments
}

\author{
Brijpal Singh*, \\ *Mechanical Engineering Department, Maharaja Surajmal Institute of Technology, C-4, \\ Janakpuri, New Delhi, 110058, India
}

†Corresponding author : brijpalsingh101@gmail.com

(Received April 6, 2017 ; Revised June 14, 2017 ; Accepted October 16, 2017)

\begin{abstract}
This aim of this study was to design the flux for low sulphur and low sulphur content in the weldments using SAW fluxes for low carbon steels. RSM technique has been used to design the number of experiments. CCD has been used as it suggests minimum number of experiments between the input and output variables. The base fluxes were selected using binary and ternary phase diagrams according to the melting point of the steel. The sulphur and phosphorus contents both enhance embrittlement and are not supposed to be good for impact strength and UTS so, these should be kept at minimum level in the welds. This study may help in selection of flux for low sulphur and low phosphorous welds. It is found that the weld sulphur and phosphorus are found minimum when $\mathrm{CaF}_{2}, \mathrm{FeMn}$ and $\mathrm{NiO}$ are $5 \%, 8 \%$ and $5 \%$ respectively.
\end{abstract}

Key Words : SAW, RSM, Optimization, Element transfer.

\section{Introduction}

Fluxes are the chemical substances that are used as a cleaning agent in welding. The SAW fluxes contain lime, silica, manganese oxide, calcium fluoride and other compounds. In SAW the weld pool is protected from the atmospheric contamination by being submerged under a blanket of granular fusible flux. In the molten state, the flux becomes conductive and provides a current path between the electrode and work piece. Fluxes can be categorized depending upon the method of manufacture, the extent to which they can affect the alloy content of the weld deposit and the effect on weld deposit properties.

The submerged arc welding is widely used for its high quality joints. In this process a large amount of flux is used in order to prevent the oxidation of the weld. The basic functions of the fluxes in SAW are to improve arc stability, to refine the weld metal and to add the alloying elements Linert, 1995, Jackson, $1960^{1,2)}$. The various ingredients of flux decide the weld composition and properties. The physical and chemical properties of flux and welding process parameters decide the transfer of various elements to the weld. The transferred elements to the welds decide the mechanical properties of the welds. The mechanism of elements transfer in SAW is very difficult because the reactions involved in the weld pool and arc column are of very complex nature. The final weld metal composition in submerged arc welding depends upon the slag metal reactions, dilution, flux used, base plate composition and wire used Fleck et al. $(1986)^{3)}$. The slag metal reactions play a major role in deciding final weld metal composition during submerged arc welding; much work is required to understand the transfer of elements from the flux. To study the elements transfer becomes more difficult as the reactions in SAW are very fast and the temperature involved is very high, so it is uncertain that the equilibrium has been achieved Chai and Eager (1981) $)^{4}$.

Davis and Bailey $(1978,1980)^{5.6)}$, concluded in their research that the final weld metal chemistry is decided by both the concentration of the element in the flux and the other substances, which are present in the flux. Tanaka et al. (1980) ${ }^{7)}$ studied the effect of flux composition on transfer of the elements silicon, manganese, titanium, boron and oxygen during submerged arc welding. Thier $(1980)^{8)}$ developed a mathematical equa- 
tion for calculating the wt $\%$ of the element based on the composition of electrode, base plate and dilution of the welds. This has been depicted in equation 1 .

$$
X w n=\left(1-D^{n}\right) ?\left(X_{E}+\Delta X\right)+D^{n} ? X_{P}
$$

Where $X_{w n}$, is the concentration wt \% of element $X$ in the $n^{\text {th }}$ run of the weld, $X_{E}$ is concentration of element $X$ in the wire electrode, $X_{P}$ is concentration of element $X$ in the parent metal, $\Delta X$, is the gain or loss of element through droplet reaction, $\mathrm{D}$ is dilution and $\mathrm{n}$ is the number of runs. From this equation it is evident as the number of runs increases the contribution of the base metal decreases. Theoretically if infinite no of runs are made then the influence of base plate is neglected.

Kim et al. (1990) ${ }^{9)}$ investigated the effect of polarity on element transfer with a silicate flux and found that significant composition differences were observed when electrode polarity was varied in DC welding. The following anodic oxidation reactions were suggested as given in 2(a) and 2 (b).

$$
\begin{aligned}
& \mathrm{M}(\text { metal })+\mathrm{nO}^{2-}=\text { Mon }(\text { slag })+2 \mathrm{n}^{\mathrm{e}-} \\
& \mathrm{O}^{2-}(\text { slag })=\mathrm{O}(\text { metal }) 2 \mathrm{e}^{-}
\end{aligned}
$$

Pandey et al. (1994) ${ }^{10)}$ investigated the effect of SAW parameters and flux basicity index on the weld chemistry and transfer of elements like $\mathrm{Mn}, \mathrm{Si}$, carbon and sulphur. The study revealed that welding current and voltage had appreciable effect on element transfer. The weld composition was tested for $\mathrm{Si}$ and $\mathrm{Mn}$, carbon and sulphur. It was observed that there was a gain of $\mathrm{Si}$ and loss on $\mathrm{Mn}$. The similar results were obtained by Kanjilal et al. $(2006)^{11)}$.

Kumar $(2011)^{12)}$ developed acidic fluxes from the dust of various commercial acidic fluxes and compared the chemical composition and mechanical properties of the weld metals. In this study they discussed the transfer of various element contents like $\mathrm{C}, \mathrm{Mn}, \mathrm{Si}, \mathrm{Cr}, \mathrm{Mo}$; it was found that the composition of weld metal made by dust were almost in the range of parent commercial fluxes.

\section{Experimental procedure}

RSM is a technique that explores the relationship between various input and output variables. The main purpose of RSM was to use a sequence of designed experiments to obtain an optimal response. In this study twenty fluxes were designed by using RSM methodology.. The base fluxes $\mathrm{CaO}, \mathrm{SiO}_{2}$ and $\mathrm{Al}_{2} \mathrm{O}_{3}$ were selected and mixed in the ratio of 7:10:2 as per binary and ternary phase diagrams and the additives $\mathrm{CaF}_{2}, \mathrm{FeMn}$ and $\mathrm{NiO}$ were added in the range of (2-8) \% .The bead on plate welds were made and 3-4 beads were laid one over the other in order to reduce the effect of dilution. The welding parameters such as voltage, current and travel speed were made constant during the welding. Chemical analysis of the bead was done by extracting powder from the top bead with the help of a drill and the transfer of manganese was calculated by a $\Delta$ Delta quantity $=$ Analyzed composition - Expected composition.

The expected composition was calculated from the below given relation equation (3)

Expected composition $=$

$$
\begin{aligned}
& \frac{\text { dilution } * \text { base plate composition }}{100}+ \\
& \frac{(100-\text { dilution }) * \text { wire composition }}{100}
\end{aligned}
$$

The design matrix is given in Table 1 while, the three levels of experimentation, wire and plate composition, the welding process parameters and the measured responses are given in Tables 2, 3, 4 and 5 respectively. The made bead on welds and the powder extracted for chemical analysis are given in Figs. 1(a) and 1(b) respectively.

\begin{tabular}{|c|c|c|c|}
\hline $\begin{array}{c}\text { No. of } \\
\text { Experiment }\end{array}$ & $\begin{array}{c}\mathrm{CaF}_{2} \text { wt } \% \\
\mathrm{~A}\end{array}$ & $\begin{array}{c}\text { FeMn } \mathrm{wt}^{0} \% \\
\text { B }\end{array}$ & $\begin{array}{c}\mathrm{NiO} \mathrm{wt} \\
\% \mathrm{C}\end{array}$ \\
\hline 1 & +1 & -1 & -1 \\
\hline 2 & 0 & +1 & 0 \\
\hline 3 & +1 & -1 & +1 \\
\hline 4 & -1 & -1 & -1 \\
\hline 5 & 0 & 0 & 0 \\
\hline 6 & 0 & 0 & 0 \\
\hline 7 & +1 & +1 & +1 \\
\hline 8 & 0 & 0 & 0 \\
\hline 9 & 0 & -1 & 0 \\
\hline 10 & +1 & 0 & 0 \\
\hline 11 & 0 & 0 & +1 \\
\hline 12 & -1 & -1 & +1 \\
\hline 13 & 0 & 0 & 0 \\
\hline 14 & 0 & 0 & 0 \\
\hline 15 & +1 & +1 & -1 \\
\hline 16 & -1 & 0 & 0 \\
\hline 17 & 0 & 0 & 0 \\
\hline 18 & 0 & 0 & -1 \\
\hline 19 & -1 & +1 & +1 \\
\hline 20 & -1 & +1 & -1 \\
\hline
\end{tabular}
For measuring sulphur and phosphorus transfer $10 \%$ dilution of the base plate was assumed. So to ensure this, four beads were laid over the other were made.

Table 1 Design matrix in coded form. 
Table 2 The three factors and their levels

\begin{tabular}{|c|c|c|c|c|}
\hline Factors & Additives & Lower Level \% & Middle Level \% & High Level \% \\
\hline $\mathrm{A}$ & $\mathrm{CaF}_{2}$ & 2 & 5 & 8 \\
\hline $\mathrm{B}$ & $\mathrm{FeMn}$ & 2 & 5 & 8 \\
\hline $\mathrm{C}$ & $\mathrm{NiO}$ & 2 & 5 & 8 \\
\hline
\end{tabular}

Table 3 The wire and plate composition

\begin{tabular}{|c|c|c|c|c|c|c|}
\hline Composition & Carbon \% & Silicon \% & Manganese \% & Sulphur \% & Phosphorus \% & Nickel \% \\
\hline Base Plate & 0.03 & 0.07 & 0.34 & 0.017 & 0.022 & - \\
\hline Wire & 0.11 & 0.09 & 0.45 & 0.021 & 0.021 & - \\
\hline
\end{tabular}

Table 4 The Welding parameters

\begin{tabular}{|c|c|c|c|}
\hline S.No. & Voltage & Current & Travel speed \\
\hline 1 & 30 volts & 475 ampere & $20 \mathrm{~cm} /$ minute. \\
\hline
\end{tabular}

\section{Optimization and flux formulation}

The fluxes still today are designed and developed by hit and trial method of experimentation. This conventional method takes more time and cost. From the conventional method, it is also difficult to cover the whole range and optimum combination of ingredients of fluxes. The hit and trial method of experimentation is not scientific and a large number of experiments are required to perform before reaching any conclusion. So, in this experiment a scientific method (DOE) has been used for experimentation. As DOE is a systematic method that can be used to determine the relationship between various factors affecting a process and the output of that process. It is used to find cause and affect relationship.

Kumar et al. 2015 ${ }^{13)}$, Roy et al. 2013 ${ }^{14)}$ used the fuzzy logic model for optimization of weld metal properties.

Table 5 Measured responses

\begin{tabular}{|c|c|c|c|c|c|c|c|c|c|c|}
\hline Flux & $\mathrm{CaF}_{2} \%$ & FeMn\% & $\mathrm{NiO} \%$ & $\begin{array}{c}\text { Weld } \\
\mathrm{S}\end{array}$ & $\begin{array}{c}\text { Weld } \\
\mathrm{P}\end{array}$ & $\begin{array}{c}\text { Sulphur } \\
\Delta \mathrm{S}\end{array}$ & $\begin{array}{c}\text { Phos } \\
\Delta \mathrm{P}\end{array}$ & $\begin{array}{c}\text { UTS } \\
\mathrm{MPa}\end{array}$ & Elong.\% & $\Delta \mathrm{Mn}$ \\
\hline 1 & 8 & 2 & 2 & 0.014 & 0.02 & -0.0057 & -0.0011 & 270.0 & 19.76 & -0.267 \\
\hline 2 & 5 & 8 & 5 & 0.015 & 0.024 & -0.0047 & 0.0029 & 318.0 & 13.20 & -0.069 \\
\hline 3 & 8 & 2 & 8 & 0.015 & 0.021 & -0.0047 & -0.0011 & 320.2 & 26.16 & -0.209 \\
\hline 4 & 2 & 2 & 2 & 0.014 & 0.02 & -0.0057 & -0.0011 & 189.8 & 7.00 & -0.267 \\
\hline 5 & 5 & 5 & 5 & 0.014 & 0.022 & -0.0057 & 0.0009 & 300.0 & 10.00 & -0.089 \\
\hline 6 & 5 & 5 & 5 & 0.013 & 0.015 & -0.0067 & -0.0061 & 320.0 & 9.80 & -0.129 \\
\hline 7 & 8 & 8 & 8 & 0.014 & 0.024 & -0.0057 & 0.0029 & 190.7 & 8.86 & -0.059 \\
\hline 8 & 5 & 5 & 5 & 0.016 & 0.019 & -0.0037 & -0.0021 & 284.7 & 10.33 & -0.099 \\
\hline 9 & 5 & 2 & 5 & 0.015 & 0.021 & -0.0047 & -0.0001 & 280.1 & 11.41 & -0.099 \\
\hline 10 & 8 & 5 & 5 & 0.015 & 0.02 & -0.0047 & -0.0011 & 292.6 & 21.03 & -0.019 \\
\hline 11 & 5 & 5 & 8 & 0.011 & 0.02 & -0.0087 & -0.0011 & 240 & 6.90 & -0.289 \\
\hline 12 & 2 & 2 & 8 & 0.011 & 0.024 & -0.0087 & 0.0029 & 175.7 & 5.82 & 0.131 \\
\hline 13 & 5 & 5 & 5 & 0.015 & 0.017 & -0.0047 & -0.0041 & 330.9 & 10.10 & -0.059 \\
\hline 14 & 5 & 5 & 5 & 0.013 & 0.019 & -0.0067 & -0.0021 & 326.5 & 16.2 & -0.049 \\
\hline 15 & 8 & 8 & 2 & 0.011 & 0.02 & -0.0087 & -0.0011 & 351.0 & 9.20 & -0.1990 \\
\hline 16 & 2 & 5 & 5 & 0.014 & 0.02 & -0.0057 & -0.0011 & 152.3 & 15.65 & -0.189 \\
\hline 17 & 5 & 5 & 5 & 0.013 & 0.021 & -0.0067 & -0.0011 & 319.5 & 15.60 & 0.061 \\
\hline 18 & 5 & 5 & 2 & 0.013 & 0.023 & -0.0067 & 0.0019 & 351 & 7.87 & -0.149 \\
\hline 19 & 2 & 8 & 8 & 0.013 & 0.02 & -0.0067 & -0.0011 & 128.8 & 13.25 & -0.109 \\
\hline 20 & 2 & 8 & 2 & 0.013 & 0.024 & -0.0067 & 0.029 & 319.5 & 13.68 & -0.109 \\
\hline
\end{tabular}




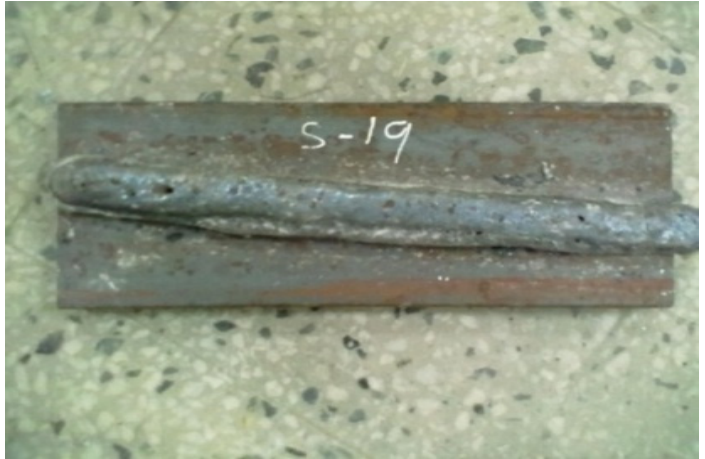

(a)

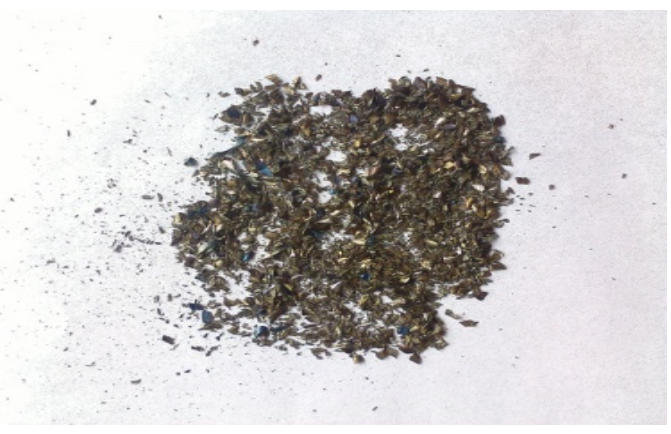

(b)

Fig. 1 (a) Bead on plate welds. (b) The powder extracted from the top bead for chemical analysis

decided the optimum levels of $\mathrm{NiO}, \mathrm{MnO}$ and $\mathrm{MgO}$ using a single MCPI for impact strength and hardness for $\mathrm{SiO}_{2}$ base fluxes. Roy et al. (2013) ${ }^{12)}$ used grey based genetic algorithm for optimization of mechanical properties of the welds. The optimal process parameters used were wire feed rate, stick out and travel speed.

\section{Fuzzy methodology}

A fuzzy logic controller is a special expert system that can be used to optimize the desired value from the set of given input and output variables. A fuzzy logic unit comprises of four modules a fuzzifier, a fuzzy rule base, an inference engine, and a defuzzifier. In fuzzy logic analysis, the fuzzifier uses membership function to fuzzify. The fuzzifier makes use of membership functions to fuzzify the signal to noise ratio that had been generated by the response. Here all the measurements are converted into fuzzy sets. The fuzzy sets represent linguistic labels which are represented by triangular shaped fuzzy number. The inference engine performs fuzzy reasoning on fuzzy rules to generate a fuzzy value by this. Finally, the defuzzifier converts the fuzzy value into a multi performance Characterization index (MPCI). The structure of the two input-one-output fuzzy logic unit and fuzzy inference system has been given in Fig. 2. The inputs are weld sulphur and weld phosphorus

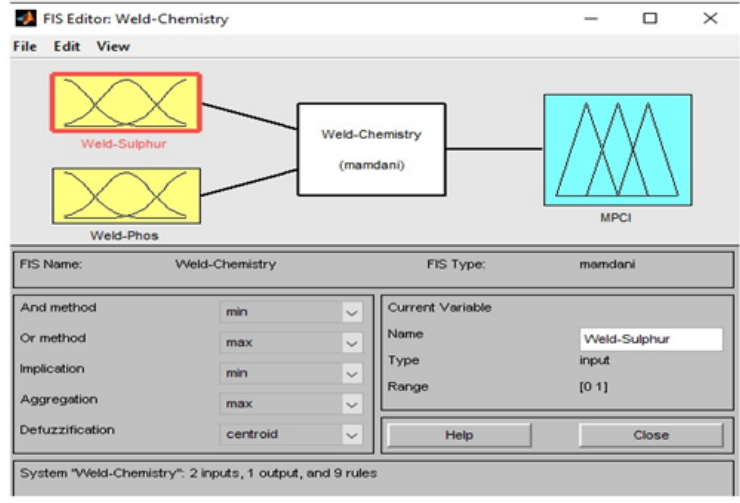

Fig. 2 Fuzzy inference system

and output is (MPCI). The $\mathrm{S} / \mathrm{N}$ ratio also has been calculated for lower sulphur and phosphorus.It has been given in equation (4). The formula for lower the better is given as below. Where $\mathrm{Y}$ is the corresponding value of the observation and $\mathrm{n}$ is the number of repetition.

$$
\frac{\mathrm{S}}{\mathrm{N}}=-10 \log _{10}\left\{\frac{\sum_{\mathrm{i}=1}^{\mathrm{n}} \mathrm{Y}_{\mathrm{i}}^{2}}{\mathrm{n}}\right\}
$$

\section{Result and Discussions}

The used fuzzy model consists of two inputs and one output which fuzzifies the input data using three triangular membership functions. These triangular memberships have been used for the two inputs and one output. This has been depicted in Figs. 3(a), 3(b) and 3(c) respectively. The fuzzy rules for this study are given in Fig. 4.Using fuzzy logic rules in the Mumdani inference, multi characteristic performance index for each experiment value has been calculated using centroid method of defuzzification as shown in Table 6. The common method of defuzzyfication is very common. In this method the results of the rules must be added together and it has a shape of triangle. Now, this triangle is cut in a horizontal line between top and bottom, a trapezoid is formed. Then the centroid of this shape is called fuzzy cancroids.

The calculated value of MPCI is highest for experiment no 2.So, it can be suggested that the flux no 2 has given the optimal result and we can say that this is the flux for which weld sulphur and weld phosphorus are minimum. The normalized values have been calculated on the basis of lower is the better so, the high values of normalized of both input gives the high MPCI. The same rank is obtained by $\mathrm{S} / \mathrm{N}$ ratio also.

In the support of the results more data has been added In Table 5. It shows that the experiment number 2 which has been selected for low sulphur and phospho- 


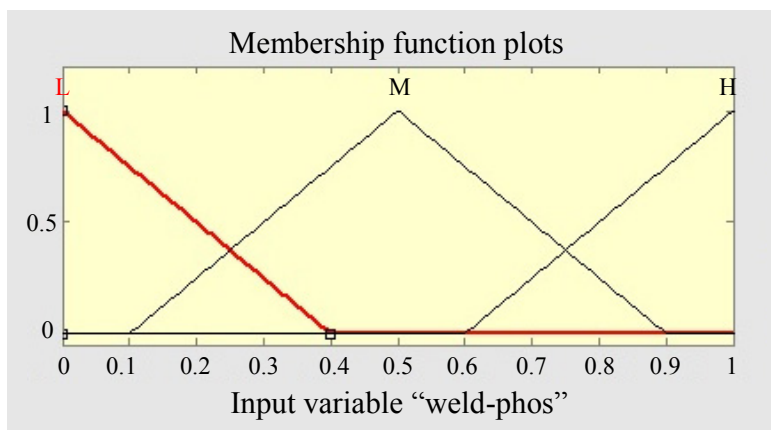

(a)

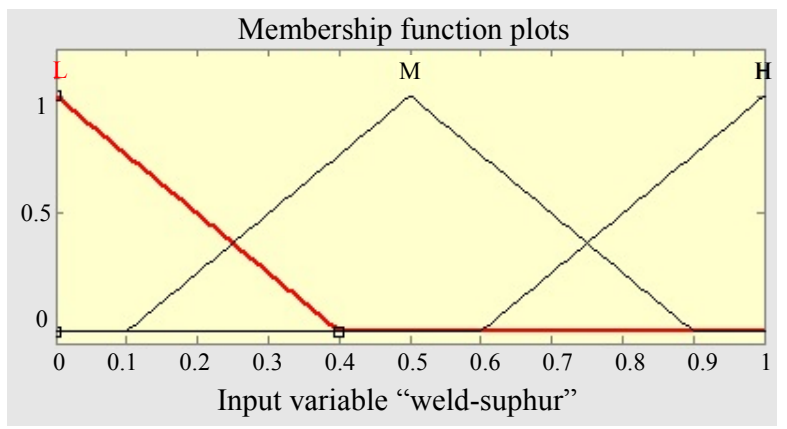

(b)

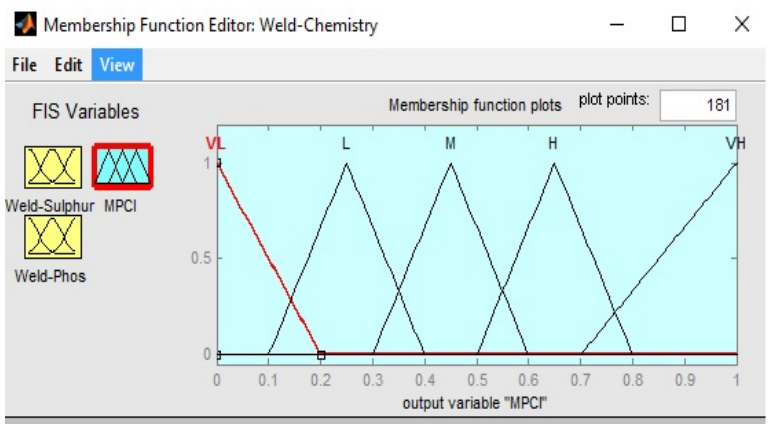

(c)

Fig. 3 (a) Membership function for weld phosphorus, (b) Membership function for weld sulphur, (c) Membership function for output

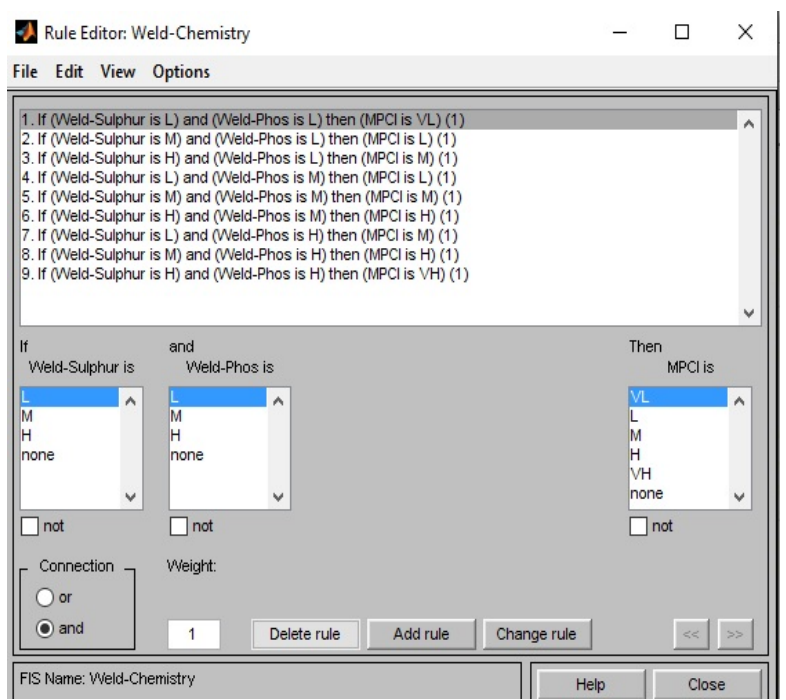

Fig. 4 Fuzzy rule base for MCPI rus is having good UTS in spite of having low percentage elongation. It also shows that this weld no 2 is having low oxygen in comparison to the other welds. Because of low oxygen in the weld the phosphorus removal may be difficult. Although, it is assumed that large oxygen in the weld removes sulphur and phosphorus from the weld. So it can be said that the removal of sulphur and phosphorus may not only depend upon the oxygen but there may be several other factors like flux composition, slag metal reactions, weld dilution reactions, basicity index of the flux. The flux no 2 is having good UTS, moderate impact strength, low oxygen content and good combination of other properties.

\section{Conclusions}

1) A scientific methodology RSM is used for design of fluxes and the fluxes are made by agglomeration technique.

2) Fuzzy logic optimization can be used for selecting a proper flux for the desired elements transfer.

3) The study reveals that $\mathrm{CaF}_{2}, \mathrm{FeMn}$ and $\mathrm{NiO}$ are $5 \%$, $8 \%$ and $5 \%$ respectively for low weld sulphur and phosphorus.

4) Such experiments should be conducted to generate a data base so that the fluxes can be selected for low sulphur and phosphorus in the welds.

ORCID: Brijpal Singh : https://orcid.org/0000-0002-5418-033X

\section{Reference}

1. G. Linert, Weld. Metallurgy, American welding society, New York, (1995)

2. C.E. Jackson, A.E. Shrubsall, Control of penetration and melting ratio with welding techniques, Welding Journal, 32(4) (1953), 172-178

3. N.A. Fleck, O. Grong, G.R. Edwards and D.K. Matlock, The role of filler wire and flux composition in submerged arc weld metal transformation kinetics, Welding Journal, 65(5) (1986), 113-121

4. C.S. Chai and T.W. Eager, Slag metal equilibrium during submerged arc welding, Metallurgical Transactions, 12B (1981), 539-547

5. M.L.E. Davis and N. Bailey, The influence of flux on element transfer during submerged arc welding, The Welding Institute, Report 66 (1978)

6. M.L.E. Davisand N. Balley, How submerged-arc flux composition influences element transfer, International Conference on Trends in Steels and Consumables for Welding. The welding Institute, London, Paper 34 (1980), 289-302

7. J. Tanaka,T. Kitada, Y. Naganawa, Y Kunisada and H. Nakagawa, Element transfer behaviour during submerged arc welding, In Proceedings of International Conference on Weld Pool Chemistry and Metallurgy, The Welding 
Table 6 Rank of various experiments

\begin{tabular}{|c|c|c|c|c|c|c|c|c|c|c|c|}
\hline Flux & $\mathrm{CaF}_{2} \%$ & $\mathrm{FeMn} \%$ & $\mathrm{NiO} \%$ & Weld S & $\begin{array}{l}\mathrm{S} / \mathrm{N} \\
\text { of } \mathrm{S}\end{array}$ & $\begin{array}{l}\text { Norm. } \\
\text { value } \mathrm{S}\end{array}$ & Weld P & $\begin{array}{l}\mathrm{S} / \mathrm{N} \\
\text { of } \mathrm{P}\end{array}$ & $\begin{array}{c}\text { Norm. } \\
\text { value P }\end{array}$ & MPCI & Rank \\
\hline 1 & 8 & 2 & 2 & 0.014 & 37.07 & 0.4 & 0.02 & 33.97 & 0.44 & 0.45 & 12 \\
\hline 2 & 5 & 8 & 5 & 0.015 & 36.47 & 0.2 & 0.024 & 32.39 & 0 & 0.1561 & 1 \\
\hline 3 & 8 & 2 & 8 & 0.015 & 36.47 & 0.2 & 0.021 & 33.55 & 0.33 & 0.2909 & 6 \\
\hline 4 & 2 & 2 & 2 & 0.014 & 37.07 & 0.4 & 0.02 & 33.97 & 0.44 & 0.45 & 13 \\
\hline 5 & 5 & 5 & 5 & 0.014 & 37.07 & 0.4 & 0.022 & 33.15 & 0.22 & 0.3329 & 9 \\
\hline 6 & 5 & 5 & 5 & 0.013 & 37.72 & 0.6 & 0.015 & 36.47 & 1 & 0.65 & 20 \\
\hline 7 & 8 & 8 & 8 & 0.014 & 37.07 & 0.4 & 0.024 & 32.39 & 0 & 0.25 & 2 \\
\hline 8 & 5 & 5 & 5 & 0.016 & 35.91 & 0 & 0.019 & 34.42 & 0.56 & 0.25 & 3 \\
\hline 9 & 5 & 2 & 5 & 0.015 & 36.47 & 0.2 & 0.021 & 33.55 & 0.33 & 0.2909 & 7 \\
\hline 10 & 8 & 5 & 5 & 0.015 & 36.47 & 0.2 & 0.02 & 33.97 & 0.44 & 0.3211 & 8 \\
\hline 11 & 5 & 5 & 8 & 0.011 & 39.17 & 1 & 0.02 & 33.97 & 0.44 & 0.65 & 19 \\
\hline 12 & 2 & 2 & 8 & 0.011 & 39.17 & 1 & 0.024 & 32.39 & 0 & 0.45 & 14 \\
\hline 13 & 5 & 5 & 5 & 0.015 & 36.47 & 0.2 & 0.017 & 35.39 & 0.78 & 0.4403 & 11 \\
\hline 14 & 5 & 5 & 5 & 0.013 & 37.72 & 0.6 & 0.019 & 34.42 & 0.56 & 0.45 & 15 \\
\hline 15 & 8 & 8 & 2 & 0.011 & 39.17 & 1 & 0.02 & 33.97 & 0.44 & 0.65 & 18 \\
\hline 16 & 2 & 5 & 5 & 0.014 & 37.07 & 0.4 & 0.02 & 33.97 & 0.44 & 0.45 & 16 \\
\hline 17 & 5 & 5 & 5 & 0.013 & 37.72 & 0.6 & 0.021 & 33.55 & 0.33 & 0.3975 & 10 \\
\hline 18 & 5 & 5 & 2 & 0.013 & 37.72 & 0.6 & 0.023 & 32.76 & 0.11 & 0.2585 & 5 \\
\hline 19 & 2 & 8 & 8 & 0.013 & 37.72 & 0.6 & 0.02 & 33.97 & 0.44 & 0.45 & 17 \\
\hline 20 & 2 & 8 & 2 & 0.013 & 37.72 & 0.6 & 0.024 & 32.39 & 0 & 0.25 & 4 \\
\hline
\end{tabular}

Institute, Cambridge, UK, 279 (1980)

8. H. Their, Metallurgical reactions in submerged arc welding, Weld Pool Chemistry and Metallurgy, International Conference, The Welding Institute, Cambridge, UK, (1980), 271-278

9. J.H. Kim, R.H Frost, D.L. Olson and D.M. Blander, Effects of electrochemical reactions on submerged arc weld metal composition, Welding Journal, 69(12) (1990), 446-453

10. N.D, Pandey, A. Bharti and S.R. Gupta, Effect of submerged arc welding parameters on element transfer, Journal of Materials Processing Technology, 40 (1994), 195-211, https://doi.org/10.1016/0924-0136(94)90486-3

11. P. Kanjilal, T.K. Pal and S.K Majumdar, Prediction of acicular ferrite from flux ingredients in submerged arc welds metals from C-Mn-steel, ISIJ International, 45(6) (2006), 876-885

https://doi.org/10.2355/isijinternational.45.876

12. V. Kumar, Development and characterization of fluxes for submerged arc welding. Ph.D Thesis, Punjabi University, Patiala, (2011)

13. A Kumar, S. Maheshwari and S.K Sharma, Fuzzy logic optimization for SAW using silica based agglomerated fluxes, Procedia Computer Science 57 (2015), 11401145, https://doi.org/10.1016/j.procs.2015.07.403

14. J. Roy, A. Majumdar, J.D. Barma, R.N. Ray and S.C. Shah, An approach for solving multi characteristic optimization of SAW process parameters by using grey based genetic algorithm, Journal of Scientific and Industrial Research, 72(6) (2013), 340-347 